\title{
Low or Moderate Intensity Aerobic Training: Its Role in Clinical and Psychological Aspects of Community Dwelling COVID-19 Asymptomatic Older Adults With Sarcopenia Symptoms
}

\section{Gopal Nambi ( $\sim$ physio_gopal@rediffmail.com )}

Prince Sattam bin Abdulaziz University https://orcid.org/0000-0002-4203-5506

Walid Kamal Abdelbasset

Prince Sattam Bin Abdulaziz University

\section{Anju Verma}

Prince Sattam Bin Abdulaziz University

\section{Arul Vellaiyan}

Prince Sattam Bin Abdulaziz University

\section{Research article}

Keywords: COVID-19, Sarcopenia, aerobic training, muscle strength, muscle mass, physical performance, kinesiophobia, Quality of life

Posted Date: October 29th, 2020

DOI: https://doi.org/10.21203/rs.3.rs-97378/v1

License: (c) (1) This work is licensed under a Creative Commons Attribution 4.0 International License.

Read Full License 


\section{Abstract}

Background: Sarcopenia is the major health concern and common consequence of COVID-19 in the aging population. Moreover, this clinical condition has not been considered in usual physical rehabilitation practice and nor its exercise protocol is well defined, which requires a meaningful study in this field.

Objective: To find and compare the low and moderate intensity aerobic training protocols on clinical and psychological effects in community dwelling COVID-19 asymptomatic older adults with Sarcopenia symptoms.

Methods: By using computer random table method the eligible participants were randomized into two groups. First group received low-intensity aerobic training (LAT; $n=38)$ and the second group received moderate-intensity aerobic training (MAT; $n=38$ ) for 8 weeks. Clinical (muscle strength, muscle mass and physical performance) and psychological (kinesiophobia and quality of life) measures were measured at baseline, at 4th week, 8th week and at 6 month follow up.

Results: Baseline demographic and clinical attributes show homogenous presentation among the study groups ( $p>0.05$ ). After eight weeks of different aerobic trainings, and at the end of 6 months follow up, the hand grip strength, $-3.0(\mathrm{Cl} 95 \%-4.16$ to -1.83$)$, chair stand test -2.7 ( -3.29 to -2.10$)$, physical performance -0.08 ( -0.10 to -0.05$)$, kinesiophobia, 4.2 (3.25 to 5.14 ), and quality of life -5.7 (-8.4 to -2.9 ) shows more improvement $(p<0.001)$ in LAT group than MAT group but in muscle mass both groups did not show any significant difference $(p>0.05)$.

Conclusion: This study reports that low intensity aerobic training exercises improve the clinical (muscle strength and physical performance) and psychological (kinesiophobia and quality of life) aspects than moderate intensity aerobic training in COVID-19 asymptomatic older adults with Sarcopenia symptoms. At the same time both types of aerobic training exercises have negligible or little role in increasing the muscle quantity - cross sectional area.

\section{Background}

The world has been suffering from corona virus disease (COVID-19) since December 2019 and it is declared as a pandemic disease by world health organization (WHO). It is a major health concern for humans, especially in the age group of 60 years and above, also, it is a social and economic burden on the society. ${ }^{1}$ Corona virus enters into the body through nasopharyngeal root and infects almost all parts of the body. The special protein present in the spikes of the corona virus attaches with the angiotensin converter enzyme 2 receptor present on the cell membrane and easily penetrates into the cell. ${ }^{2}$ People infected with COVID-19 not only shows it's signs and symptoms, but also show it's high life threatening risks according to the comorbidities such as; age above 60 years, respiratory problems, cardiac problems and diabetes. ${ }^{3}$ It is observed that, patients with COVID-19 undergoing physical inactivity, sedentary activity; prolong bed rest or sometimes on ventilator therapy may develop muscle weakness at a later stage. This group of population is also suffer from muscle pain; muscle atrophy, weight loss and 
anorexia. ${ }^{1}$ Sarcopenia is one such major issue in COVID-19 scenario which needs to be taken care of in the physiotherapy context.

Sarcopenia is the major health concern and common consequence of COVID-19 in the aging population. The word, Sarcopenia (Greek, Sarx for "flesh" and Penia for "loss") has been coined by Irwin Rosenberg in 1988, and defined sarcopenia as a state of deterioration of muscle mass and its function by aging. ${ }^{4}$ In 2018, European Working Group on Sarcopenia in Older People (EWGSOP) recognized Sarcopenia as a disease of muscles with an international classification code of ICD-10-MC, which if untreated leads to poor quality of life and high mortality rate. ${ }^{5}$ The number of sarcopenia admission in hospitals has increased to 5 times that of the regular time in this COVID-19 situation. ${ }^{6}$ It is clinically characterized by diminished muscle functions with muscle atrophy. ${ }^{7}$ Sarcopenia is classified into primary and secondry, the primary type of sarcopenia can be seen in aging populations while the secondary type of sarcopenia is associated with other systemic diseases. ${ }^{8}$

In this present COVID-19 scenario, the requirement of social isolation leads physical inactivity and sedentary life style which accelerates muscle atrophy and diminish the muscle function. ${ }^{9}$ It also shows physiological changes in our body such as inflammatory changes, reduced albumin, decrease mitochondrial activities, disturbed neuromuscular junction conduction, hormonal imbalances, anorexia, insomnia, weight reduction, myalgia, loss of muscle mass and its properties. ${ }^{10,11}$ The inflammatory biomarker analysis shows increased C-reactive protein (CRP) and other inflammatory cytokines such as TNF-a, IL-1 and II-6, these changes are due to ACE2 receptor mechanism. The changes in inflammatory cytokines are the causes of anorexia, insomnia and altered taste sensation. ${ }^{12,13}$ The main cause of weight reduction and myalgia is physical inactivity during this lock down phase following COVID-19 which was observed by Sheahan et al on animal studies. ${ }^{14}$ Considerable number of aged patients diagnosed with COVID-19 has respiratory problems, this result in secondary sarcopenia and such patients were recommended to do regular exercises to prevent these consequences. ${ }^{15}$

In this pandemic situation sarcopenia may cause high rate of mortality and physical disability. Izquierdo $M$ et al stated that regular physical activities and exercise therapy is required to maintain the muscle mass and prevent atrophy in geriatric patients over the age of $60 .{ }^{16}$ In the same way, aged patients who developed sarcopenia during COVID - 19 require regular physical activity and exercise to maintain the physiological and psychological traits. Furthermore, the recognition of sarcopenia as a high consideration for adverse health condition in aged COVID-19 patients has ignited a question for the researchers to attempt to devise an exercise protocol to overcome these consequences. Also, this clinical condition has not been considered in usual physical rehabilitation practice and nor its exercise protocol is well defined, which requires a meaningful study in this field. Hence this study was aimed to find and compare the different aerobic training protocols on clinical and psychological effects in community dwelling COVID-19 asymptomatic older adults with Sarcopenia symptoms. The outcomes of the study could provide a new evidence and clear idea about the selection of exercise protocols in sarcopenia in 
clinical practice. The reports may also helpful for the therapists to prevent, delay, treat and reverse the symptoms of Sarcopenia in COVID-19 infection.

\section{Methods}

\section{Trial Design}

This is a randomized, double-blinded, prospective, controlled study conducted from January 2020 and August 2020. The study obtained the previous study ethical approval from department of ethical committee (DEC), Prince Sattam Bin Abdulaziz University, Al-Kharj, Saudi Arabia with the reference number of RHPT/020/044. The participant's consent form, intervention procedures and the outcome measures used were also approved by the DEC. All the participants selected for the final study were instructed to complete the written informed consent form and they were undergone for baseline demographic and clinical measurements. By using computer random table - simple random sampling method the participants were randomized and allocated into three groups. First group received lowintensity aerobic training $(L E T ; n=38)$ and the second group received moderate-intensity aerobic training $(\mathrm{MET} ; \mathrm{n}=38)$ for 8 weeks.

\section{Participants}

Participants were referred from local and government hospitals in Al-Kharj and Riyadh region of Saudi Arabia. The study registered both genders with the age range of 60-80 years with the positive diagnosis of asymptomatic COVID-19 infection. Sarcopenia (skeletal muscle loss) was identified through appendicular skeletal muscle mass index (ASMI, kg/m2). Based on AWGS criteria, ASMI score < $7.0 \mathrm{~kg} / \mathrm{m} 2$ for men and $<5.7 \mathrm{~kg} / \mathrm{m} 2$ for women were diagnosed as Sarcopenia ${ }^{17}$ and were included in the study. Subjects with low muscle mass in observation, low hand grip strength $(<24 \mathrm{~kg}$ for men or $<16 \mathrm{~kg}$ for women) and slow gait speed $(<0.7 \mathrm{~m} / \mathrm{sec}$ ) were included. Participants with prior exercise training, under medication, history of lower limb surgeries, fractures, cardiac problems, respiratory problems, neurological problems, systemic problems and any other contra indications for aerobic training were excluded. The Fig. 1 shows the flow of study participants throughout the study.

\section{Intervention}

Participants $(n=38)$ in LAT group underwent low-intensity aerobic training for 8 weeks. All the participants were instructed about the guidelines for performing the LAT exercises by a trained physiotherapist with proper COVID-19 guidelines. The exercises performed by the participants were maintained in an exercise log book and was checked every week by a physiotherapist. Before every session, the vital signs such as temperature, blood pressure (BP), oxygen saturation, heart rate and physical status were measured. If the vital signs were not suitable, like temperature $>38^{\circ} \mathrm{C}, \mathrm{BP}>$ $160 / 100 \mathrm{mmHg}$ and pulse rate $>100$ beat per minute or $<50$ beat per minute, participants were instructed not to do exercises on that day. 
The intensity of the given exercise can be measured through maximum heart rate (MHR) and it can be calculated by subtracting the participant age from 220. In low intensity aerobic exercises 40 to 50 percentage of maximum heart rate can be used. Each session started with 15 minutes of warm-up, which includes stretching of upper limb and lower limb muscles. Following warm up, the participants were instructed do 30 minutes of low-intensity aerobic training (LAT) exercises, which includes 20 minutes of treadmill (Reebok Fitness, GT50) and 10 minutes of cycle ergometer (JX Fitness, JX-7056), followed with 10 minutes of cool down. In moderate intensity exercises the same protocol has been followed, but the intensity of exercises was fixed between $50 \%$ to $70 \%$ of MHR. ${ }^{18,19}$

The progressive resistance training (PRT) was prescribed to all the participants in both the groups with weights based on individual personal strength assessment basis. The optimum resistance required for the muscle groups were decided based on one repetition maximum (RM). The major group muscles such as shoulder flexors, shoulder extensors, shoulder abductors, elbow flexors, elbow extensors, hip flexors, hip extensors, knee flexors, knee extensors, abdominal and back muscles were trained. Each group of muscles was trained for 10 repetitions for 3 sets with a rest period of 5 minutes. The resistance was increased gradually as per the individual requirements and the training was given 4 days in a week for 8 weeks. $^{20}$

\section{Outcome measures}

\section{Hand grip strength}

It is a simple and cost effective test to measure the upper limb strength and it was measured with handheld dynamometer (Camry digital hand dynamometer, EH $101-17$ ). The participant was asked to press the handle as much as possible and the scores were noted. Three measurements were taken and the average value was included for data analysis and it is a valid and reliable tool to measure the upper limb strength. ${ }^{21}$

\section{Chair stand test}

It is the test to measure the lower limb muscle strength, which measures the amount of time the participant taken to rise from the sitting position for five times without any support. It was measured in seconds and reliable and validated test to measure lower limb muscle strength. ${ }^{22}$

\section{Muscle quantity}

Muscle quantity or muscle mass was measured with Magnetic resonance imaging (MRI) scan (Philips Ingenia, 1.5 TS, MA, USA) and it is a non-invasive type of measurement. The three major muscle cross sectional areas such as mid of arm (biceps), mid of thigh (quadriceps) and mid-calf muscles were measured. ${ }^{23}$

\section{Physical performance}


It is measured with gait speed test and the participant was asked to walk fast for 4 minutes and the speed was measured with digital stop watch. It is a reliable, simple and safe test to measure the physical performance in Sarcopenia patients. ${ }^{24}$

\section{Kinesiophobia}

Tampa scale of kinesiophobia (TSK - 11) was used to measure the fear of movement due to muscle weakness. It consists of 11 questions that include somatic factors and activity avoidance and was measured in 4 point likert scale. Highest scores indicate maximum fear and lowest scores indicate minimum fear of movement. It is a reliable and valid tool to measure kinesiophobia in aged patients with Sarcopenia. ${ }^{25}$

\section{Quality of life}

It was measured subjectively by SarQol questionnaire and the participant was asked to complete the questionnaire by himself. It measures the physical, psychological and social aspects of health of sarcopenia patients and it is a reliable and valid tool. ${ }^{26}$

\section{Sample size}

The number of participants required was calculated through a basic data from the previous pilot study. ${ }^{27}$ The primary outcome variable selected was hand grip strength and 35 participants were required in each group with the objective of improving mean difference $40 \%$ and standard deviation of 2 . When considering $10 \%$ drop out the number of subjects were increased to 38 in each group and totally 76 participants were recruited. The power of the study was set at $80 \%$ and the significance level was 0.05 and the sample size was calculated using G*Power (version 3.1.9.7) statistical science software.

\section{Statistical analysis}

The participants' demographic and clinical characters were presented and tabulated and analyzed for study homogeneity using Kolmogorov-Smirnov test. The baseline, after 4 weeks, 8 weeks and 6 months follow up measurements of primary and secondary variables were measured and presented as mean \pm standard deviation (SD). Intention to treat analysis was presumed in the treatment effect analysis with replacing missing data. The $2 \times 4$ multiple analysis of variance (MANOVA) was performed to measure the group $\times$ time effect of each variables. Independent $t$ test was performed to find the difference between the treatment groups and repeated measures analysis of variance (ANOVA) was performed to find the intra group effects. The whole statistical analysis was performed with IBM SPSS Statistics for Windows (version 20.0) and the statistical significant value was set at 0.05 .

\section{Results}

Out of 121 screened participants, sixteen participants had other systemic problems, nine had joint degeneration, eight were awaiting some surgery and twelve participants were not given consent to 
participate in the study and $(\mathrm{N}=76)$ were eligible to participate and they were randomized into two groups. The statistical test was conducted under intention to treat analysis principle and three subjects from LAT group and four subjects from MAT group were dropped at the end of 6 month follow up analysis (Fig. 1). The participant's demographic and clinical characters were analyzed between the groups for the study homogeneity by using Kolmogorov-Smirnov test and the test shows no significant difference in age, height, weight and body mass index (BMI) measures $(p>0.05)$ and the data represents

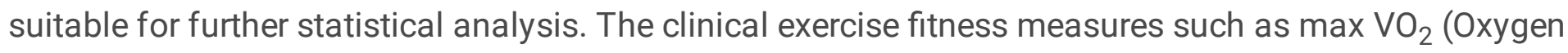
volume) and heart beat were measured for identifying to involve in aerobic exercise training, it also shows no significant difference and the data $(p>0.05)$ were presented as mean and SD in Table 1.

Table 1

Demographic details of low intensity and moderate intensity aerobic training groups

\begin{tabular}{|lllll|}
\hline Sr. No & Variable & LAT Group & MAT Group & p-value \\
\hline 1 & Age $(\mathrm{y})$ & $63.2 \pm 3.1$ & $64.1 \pm 3.2$ & 0.217 \\
\hline 2 & Height $(\mathrm{m})$ & $1.66 \pm 0.22$ & $1.67 \pm 0.21$ & 0.839 \\
\hline 3 & Weight $(\mathrm{kg})$ & $74.6 \pm 3.1$ & $75.8 \pm 3.5$ & 0.117 \\
\hline 5 & $\mathrm{BMI}\left(\mathrm{kg} / \mathrm{m}^{2}\right)$ & $23.1 \pm 1.6$ & $22.8 \pm 1.7$ & 0.430 \\
\hline 6 & $\mathrm{VO}_{2}$ peak $(\mathrm{ml} / \mathrm{kg} / \mathrm{min})$ & $29.5 \pm 1.8$ & $30.2 \pm 1.7$ & 0.085 \\
\hline $\begin{array}{l}\text { LAT }- \text { Low intensity aerobic training, MAT - Moderate intensity aerobic training, BMI - Body mass } \\
\text { index, VO }\end{array}$ & & & 0.057 \\
\hline
\end{tabular}

The $2 \times 4$ (group $\times$ time) multiple analysis of variance (MANOVA) of primary variables (hand grip strength and chair stand test) shows significant difference $(p<0.001)$, but muscle quantity (mid-arm, mid-thigh and mid-calf) failed to show the difference $(p>0.05)$ between the groups at various intervals. The baseline primary variables did not show any significant difference $(p>0.05)$ between LAT and MAT groups. At four weeks of intervention, hand grip strength 1.2 ( $\mathrm{Cl} 95 \% 0.17$ to 2.22 ) and chair stand test $1.2(\mathrm{Cl} 95 \%-1.74$ to -0.65$)$, improved $(\mathrm{p}<0.001)$ in LAT group than MAT group but not in muscle quantity mid-arm - 0.3 ( $\mathrm{Cl} 95 \%-2.42$ to 1.82), mid-thigh 0.6 ( $\mathrm{Cl} 95 \%-2.02$ to 3.22 ) and mid-calf - 1.2 (Cl 95\% -3.57 to 1.17) measurements. The same changes have been observed in 8 weeks and 6 months follow up. At the end of 6 months follow up, again the hand grip strength -3.0 (CI 95\%-4.16 to -1.83) and chair stand test -2.7 ( $\mathrm{Cl} 95 \%-3.29$ to -2.10$)$, improved $(\mathrm{p}<0.001)$ in LAT group than MAT group but not in muscle quantity mid-arm -1.7 ( $\mathrm{Cl} 95 \%-3.96$ to 0.56$)$, mid-thigh -3.1 (Cl 95\% -5.98 to -0.21$)$ and mid-calf -2.5 (Cl $95 \%-4.94$ to -0.05 ) measurements (Table $2 \& 3$ ). When calculated the effect size, the overall changes noted in hand grip strength $(d=1.17)$ and chair stand test $(d=1.40)$ of LAT group were categorized into large effect. The visual representation in Fig. 2 also shows more improvements in LAT group than MAT group. 
Table 2

Pre and post analysis of low intensity and moderate intensity aerobic training groups

\begin{tabular}{|c|c|c|c|c|c|}
\hline Sr. No & Variable & Duration & LAT Group & MAT Group & p-value \\
\hline \multirow[t]{5}{*}{1} & Hand grip strength & Base line & $28.8 \pm 2.1$ & $29.2 \pm 2.3$ & 0.431 \\
\hline & \multirow[t]{4}{*}{ (Hand dynamometer - kg) } & 4 weeks & $29.3 \pm 2.2$ & $30.5 \pm 2.3$ & $0.022^{*}$ \\
\hline & & 8 weeks & $32.4 \pm 2.4$ & $30.8 \pm 2.3$ & $0.004^{*}$ \\
\hline & & 6 months & $34.3 \pm 2.7$ & $31.3 \pm 2.4$ & $0.001 *$ \\
\hline & & $\mathrm{p}$-value & $0.001^{\star *}$ & $0.001^{\star \star}$ & \\
\hline \multirow[t]{5}{*}{2} & \multirow{5}{*}{$\begin{array}{l}\text { Chair stand test } \\
\text { (Number of stands) }\end{array}$} & Base line & $11.2 \pm 1.1$ & $11.4 \pm 1.2$ & 0.451 \\
\hline & & 4 weeks & $13.3 \pm 1.2$ & $12.1 \pm 1.2$ & $0.001 *$ \\
\hline & & 8 weeks & $14.5 \pm 1.3$ & $13.8 \pm 1.3$ & $0.021 *$ \\
\hline & & 6 months & $16.9 \pm 1.3$ & $14.2 \pm 1.3$ & $0.001 *$ \\
\hline & & $\mathrm{p}$-value & $0.001^{\star \star}$ & $0.443^{\star}$ & \\
\hline \multirow[t]{5}{*}{3} & \multirow{5}{*}{$\begin{array}{l}\text { Muscle quantity } \\
\text { (MRI - mid arm: } \mathrm{cm}^{2} \text { ) }\end{array}$} & Base line & $55.8 \pm 4.5$ & $55.6 \pm 4.7$ & 0.850 \\
\hline & & 4 weeks & $56.2 \pm 4.5$ & $55.9 \pm 4.8$ & 0.779 \\
\hline & & 8 weeks & $57.4 \pm 4.6$ & $56.5 \pm 5.0$ & 0.416 \\
\hline & & 6 months & $58.8 \pm 4.8$ & $57.1 \pm 5.1$ & 0.138 \\
\hline & & $\mathrm{p}$-value & $0.001^{\star *}$ & $0.001^{\star *}$ & \\
\hline \multirow[t]{5}{*}{4} & Muscle quantity & Base line & $64.7 \pm 5.6$ & $65.1 \pm 5.8$ & 0.760 \\
\hline & \multirow[t]{4}{*}{$\left(\mathrm{MRI}\right.$ - mid thigh: $\left.\mathrm{cm}^{2}\right)$} & 4 weeks & $65.3 \pm 5.7$ & $65.9 \pm 5.8$ & 0.650 \\
\hline & & 8 weeks & $68.5 \pm 5.9$ & $67.4 \pm 5.9$ & 0.419 \\
\hline & & 6 months & $70.5 \pm 6.5$ & $68.2 \pm 6.1$ & $0.035^{\star}$ \\
\hline & & $\mathrm{p}$-value & 0.001 ** & 0.001 ** & \\
\hline \multirow[t]{5}{*}{5} & Muscle quantity & Base line & $62.9 \pm 5.1$ & $61.8 \pm 4.9$ & 0.340 \\
\hline & \multirow[t]{4}{*}{ (MRI - mid calf: $\mathrm{cm}^{2}$ ) } & 4 weeks & $63.6 \pm 5.2$ & $62.4 \pm 5.2$ & 0.317 \\
\hline & & 8 weeks & $65.2 \pm 5.2$ & $63.2 \pm 5.2$ & 0.097 \\
\hline & & 6 months & $66.3 \pm 5.4$ & $63.8 \pm 5.3$ & $0.045^{\star}$ \\
\hline & & $\mathrm{p}$-value & $0.001^{\star *}$ & $0.001^{\star *}$ & \\
\hline
\end{tabular}

*Significant, LAT - Low intensity aerobic training, MAT - Moderate intensity aerobic training, MRI Magnetic resonance imaging, TSK - Tamba scale of kinesiophobia, SarQol - Sarcopenia quality of life 


\begin{tabular}{|c|c|c|c|c|c|}
\hline Sr. No & Variable & Duration & LAT Group & MAT Group & p-value \\
\hline \multirow[t]{5}{*}{6} & Physical performance & Base line & $1.18 \pm 0.03$ & $1.17 \pm 0.04$ & 0.221 \\
\hline & \multirow[t]{4}{*}{ (Gait speed - m/s) } & 4 weeks & $1.23 \pm 0.03$ & $1.18 \pm 0.04$ & $0.001^{*}$ \\
\hline & & 8 weeks & $1.30 \pm 0.04$ & $1.22 \pm 0.05$ & $0.001^{*}$ \\
\hline & & 6 months & $1.32 \pm 0.05$ & $1.24 \pm 0.05$ & $0.001^{*}$ \\
\hline & & $\mathrm{p}$-value & $0.001 * *$ & $0.001 * \star$ & \\
\hline \multirow[t]{5}{*}{7} & \multirow{4}{*}{$\begin{array}{l}\text { Kinesiophobia } \\
\text { (TSK-11) }\end{array}$} & Base line & $32.8 \pm 3.2$ & $31.8 \pm 2.9$ & 0.157 \\
\hline & & 4 weeks & $25.3 \pm 2.7$ & $27.3 \pm 2.5$ & $0.001^{*}$ \\
\hline & & 8 weeks & $20.2 \pm 2.3$ & $22.5 \pm 2.4$ & $0.001^{*}$ \\
\hline & & 6 months & $15.9 \pm 1.8$ & $20.1 \pm 2.3$ & $0.001^{*}$ \\
\hline & & $\mathrm{p}$-value & $0.001 * \star$ & $0.001 * *$ & \\
\hline \multirow[t]{5}{*}{8} & \multirow{5}{*}{$\begin{array}{l}\text { Quality of life } \\
\text { (SarQol) }\end{array}$} & Base line & $56.8 \pm 5.7$ & $57.2 \pm 5.5$ & 0.756 \\
\hline & & 4 weeks & $61.3 \pm 5.9$ & $58.2 \pm 5.5$ & $0.020 *$ \\
\hline & & 8 weeks & $65.4 \pm 6.1$ & $60.5 \pm 5.6$ & $0.001^{*}$ \\
\hline & & 6 months & $67.9 \pm 6.3$ & $62.2 \pm 5.8$ & $0.001^{* *}$ \\
\hline & & $\mathrm{p}$-value & $0.001 * \star$ & $0.001 * \star$ & \\
\hline
\end{tabular}


Table 3

Pre and post mean difference and confidence interval (upper limit and lower limit) scores of low intensity and moderate intensity aerobic training groups.

\begin{tabular}{|c|c|c|c|c|c|}
\hline \multirow[t]{2}{*}{ Variable / Time } & & Baseline & $\begin{array}{l}4 \\
\text { weeks }\end{array}$ & $6 \mathrm{mc}$ & \\
\hline & & \multicolumn{4}{|c|}{ Mean difference Cl 95\% (Upper limit - Lower limit) } \\
\hline \multirow[t]{2}{*}{$\begin{array}{l}\text { Hand grip } \\
\text { strength }\end{array}$} & $\begin{array}{l}\text { LAT } x \\
\text { MAT }\end{array}$ & $\begin{array}{l}0.4(-0.60 \text { to } \\
1.40)\end{array}$ & $\begin{array}{l}1.2(0.17 \text { to } \\
2.22)\end{array}$ & $\begin{array}{l}-1.6(-2.67 \text { to } \\
-0.52)\end{array}$ & $\begin{array}{l}-3.0(-4.16 \text { to } \\
-1.83)\end{array}$ \\
\hline & $\begin{array}{l}P- \\
\text { value }\end{array}$ & 0.431 & 0.022 & 0.004 & 0.001 \\
\hline \multirow[t]{2}{*}{ Chair stand test } & $\begin{array}{l}\text { LAT } x \\
\text { MAT }\end{array}$ & $\begin{array}{l}0.2(-0.32 \text { to } \\
0.72)\end{array}$ & $\begin{array}{l}-1.2(-1.74 \text { to } \\
-0.65)\end{array}$ & $\begin{array}{l}-0.7(-1.29 \text { to } \\
-0.10)\end{array}$ & $\begin{array}{l}-2.7(-3.29 \text { to } \\
-2.10)\end{array}$ \\
\hline & $\begin{array}{l}P- \\
\text { value }\end{array}$ & 0.451 & 0.001 & 0.021 & 0.001 \\
\hline \multirow{2}{*}{$\begin{array}{l}\text { Mid-arm } \\
\text { CSA }\end{array}$} & $\begin{array}{l}\text { LAT } x \\
\text { MAT }\end{array}$ & $\begin{array}{l}-0.2(-2.30 \text { to } \\
1.90)\end{array}$ & $\begin{array}{l}-0.3(-2.42 \text { to } \\
1.82)\end{array}$ & $\begin{array}{l}-0.9(-3.09 \text { to } \\
1.29)\end{array}$ & $\begin{array}{l}-1.7(-3.96 \text { to } \\
0.56)\end{array}$ \\
\hline & $\begin{array}{l}\mathrm{P}- \\
\text { value }\end{array}$ & 0.850 & 0.779 & 0.416 & 0.138 \\
\hline \multirow{2}{*}{$\begin{array}{l}\text { Mid-thigh } \\
\text { CSA }\end{array}$} & $\begin{array}{l}\text { LAT } x \\
\text { MAT }\end{array}$ & $\begin{array}{l}0.4(-2.2 \text { to } \\
3.0)\end{array}$ & $\begin{array}{l}0.6(-2.02 \text { to } \\
3.22)\end{array}$ & $\begin{array}{l}-1.1(-3.79 \text { to } \\
1.59)\end{array}$ & $\begin{array}{l}-3.1(-5.98 \text { to } \\
-0.21)\end{array}$ \\
\hline & $\begin{array}{l}P- \\
\text { value }\end{array}$ & 0.760 & 0.650 & 0.419 & 0.035 \\
\hline \multirow{2}{*}{$\begin{array}{l}\text { Mid-calf } \\
\text { CSA }\end{array}$} & $\begin{array}{l}\text { LAT } x \\
\text { MAT }\end{array}$ & $\begin{array}{l}-1.1(-3.38 \text { to } \\
1.18)\end{array}$ & $\begin{array}{l}-1.2(-3.57 \text { to } \\
1.17)\end{array}$ & $\begin{array}{l}-2.0(-4.37 \text { to } \\
0.37)\end{array}$ & $\begin{array}{l}-2.5(-4.94 \text { to } \\
-0.05)\end{array}$ \\
\hline & $\begin{array}{l}P- \\
\text { value }\end{array}$ & 0.340 & 0.317 & 0.097 & 0.045 \\
\hline \multirow[t]{2}{*}{$\begin{array}{l}\text { Physical } \\
\text { performance }\end{array}$} & $\begin{array}{l}\text { LAT } x \\
\text { MAT }\end{array}$ & $\begin{array}{l}-0.01(-0.02 \text { to } \\
0.00)\end{array}$ & $\begin{array}{l}-0.05(-0.06 \text { to } \\
-0.03)\end{array}$ & $\begin{array}{l}-0.08(-0.10 \text { to } \\
-0.05)\end{array}$ & $\begin{array}{l}-0.08(-0.10 \text { to } \\
-0.05)\end{array}$ \\
\hline & $\begin{array}{l}P- \\
\text { value }\end{array}$ & 0.221 & 0.001 & 0.001 & 0.001 \\
\hline \multirow[t]{2}{*}{ Kinesiophobia } & $\begin{array}{l}\text { LAT } x \\
\text { MAT }\end{array}$ & $\begin{array}{l}-1.0(-2.39 \text { to } \\
0.39)\end{array}$ & $\begin{array}{l}2.0(0.81 \text { to } \\
3.18)\end{array}$ & $\begin{array}{l}2.3(1.22 \text { to } \\
3.37)\end{array}$ & $\begin{array}{l}4.2(3.25 \text { to } \\
5.14)\end{array}$ \\
\hline & $\begin{array}{l}P- \\
\text { value }\end{array}$ & 0.157 & 0.001 & 0.001 & 0.001 \\
\hline Quality of life & $\begin{array}{l}\text { LAT } x \\
\text { MAT }\end{array}$ & $\begin{array}{l}0.4(-2.16 \text { to } \\
2.96)\end{array}$ & $\begin{array}{l}-3.1(-5.7 \text { to } \\
-0.4)\end{array}$ & $\begin{array}{l}-4.9(-7.5 \text { to } \\
-2.2)\end{array}$ & $\begin{array}{l}-5.7(-8.4 \text { to } \\
-2.9)\end{array}$ \\
\hline
\end{tabular}

LAT - Low intensity aerobic training, MAT - Moderate intensity aerobic training, CSA - Cross sectional area 


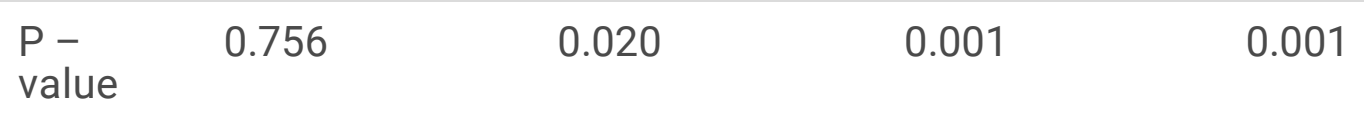

LAT - Low intensity aerobic training, MAT - Moderate intensity aerobic training, CSA - Cross sectional area

The secondary outcome measures such as; physical performance, kinesiophobia and quality of life were measured with gait speed, TSK-11 and SarQoL. The baseline scores did not show any significant difference $(p>0.05)$ between LAT and MAT groups. After four weeks of intervention, physical performance, -0.05 ( $\mathrm{Cl} 95 \%-0.06$ to -0.03 ), kinesiophobia level 2.0 ( $\mathrm{Cl} 95 \% 0.81$ to 3.18 ), and quality of life -3.1 ( $\mathrm{Cl} 95 \%-5.7$ to -0.4$)$ improved $(\mathrm{p}<0.001)$ in LAT group than MAT group. The same growth can be noted in 8 weeks and 6 months follow up. At the end of 6 months follow up, again the physical performance, -0.08 ( $\mathrm{Cl} 95 \%-0.10$ to -0.05 ), kinesiophobia level 4.2 (Cl 95\% 3.25 to 5.14 ) and quality of life -5.7 (Cl 95\% -8.4 to -2.9) showed more improvement $(p<0.001)$ in LAT group than MAT group (Table 2 \&3). When calculated the effect size, the LAT group noted larger effects in physical performance $(d=1.6)$, kinesiophobia level $(d=2.04)$ and quality of life $(d=0.94)$ when compared to MAT group. The graphical presentation in Fig. 2 also shows more changes in the LAT group than MAT group.

\section{Discussion}

This trial was conducted to compare and investigate the clinical (muscle strength, muscle mass and physical performance) and psychological (kinesiophobia and quality of life) effects of low or moderate intensity aerobic training in community dwelling COVID-19 asymptomatic older adults with Sarcopenia symptoms. The Sarcopenia and physical frailty in older people: multicomponent treatment strategies (SPRINTT) guidelines offered health practitioners to provide proper treatment strategies for older adults with Sarcopenia, which could be followed in COVID-19 scenario. ${ }^{28}$ Izquierdo $\mathrm{M}$ et al noted that older persons with Sarcopenia admitted in hospital or house quarantine for COVID-19 have to undergo regular exercise training for better outcomes. ${ }^{29}$ The reports of this trial stated that low intensity aerobic training (LAT) had better effects than moderate intensity aerobic training (MAT) in clinical and psychological effects and no or little change in muscle mass between the two groups.

Generally, aerobic exercises are safe physical activities which lead to whole body activation and induce the skeletal muscle properties. It promotes overall energy expenditure; improve physical fitness and pathway for healthy aging. ${ }^{30}$ In respect to muscle properties, all type of aerobic exercises controls the adverse effects of aging, such as on inflammation process, mitochondrial function, cell apoptosis and insulin activity. ${ }^{31}$ Among the other types of aerobic training, LAT improves overall endurance by activating skeletal muscle oxidative capacity and improves blood flow to the cell. This is the greatest demand of mitochondria in the cell during physical activity and it becomes enhanced during LAT exercises. ${ }^{32}$ LAT exercise activates the muscle protein peroxisome proliferator activated receptor gamma coactivator-1 (PGC-1) and facilitates mitochondrial function and increase the energy expenditure. ${ }^{31}$ 
Regarding muscle strength (hand grip strength, chair stand test and physical performance test), our reports show significant difference between the two groups. Goto $\mathrm{K}$ et al observed that the differences in the muscle strength in LAT and MAT exercise could be due to differences in energy metabolism or differences in training duration. ${ }^{33}$ The intra group analysis shows both groups have shown significant changes in muscle strength irrespective of exercise intensity. However, low intensity aerobic training group shows MCID (hand grip strength - 3.00, chair stand test -2.70 and physical performance test 0.08 ) than moderate intensity aerobic training group.

At the same time, muscle quantity (arm, thigh and calf) - CSA did not show any statistical difference in LAT and MAT exercises which is in agreement with Pasini $E$ et al, because these exercises did not have any role in altering the number and size of fast twitch muscle fibers. ${ }^{34}$ Cadore EL et al., stated that the order of performing exercises (aerobic training followed with resistance training) plays an important role in improving the muscle strength and muscle mass, ${ }^{35}$ but in our study aerobic training was given first and then resistance training was given. This could be the cause for no changes in the muscle mass in both groups and the exact mechanism behind the effects of order of training was not clearly found.

Furthermore, it is observed that the little differences in LAT or MAT aerobic training in muscle quantity could be due to either demographic characters or exercise parameters. ${ }^{36}$

Moreover, inclusion of resistance exercises in the form of PRT would induce and recruit new satellite cells into the weak muscle fibers and increase the number of myonucleus. This process would increases the strength and power of the muscle fibers and it depends upon age of the person, food status, and type of training. During resistance exercises the muscle fibers secrete muscle inflammatory cytokines which stimulate the satellite cells and increase the myonucleus in the muscles. ${ }^{37}$ Bowen TS noticed that in older adults there is substantial reduction in several muscle inflammatory cytokines and these hormonal and inflammatory changes have helped for the improvement in muscle strength and physical performance after LAT and MAT exercises. ${ }^{38}$

Improving muscle strength is closely related with the improvement in activities of daily living (ADL), which may decrease kinesiophobia (fear of movement and fall) status. These overall changes improved the quality of life (QOL) of COVID-19 infected older adults with Sarcopenia symptoms as agreed by Rejeski et al, ${ }^{39}$ and Binder et al ${ }^{40}$ but against by Holviala et al. ${ }^{41}$ The reports also suggest that LAT and MAT combined with progressive resistance training improved the psychological effects in older adults with Sarcopenia. Moreover, greater reduction in kinesiophobia status and improvement in quality of life were noted in LAT group than MAT group with MCID score (kinesiophobia - 4.2, quality of life - 5.7) Granacher et $\mathrm{al}^{42}$ have observed that PRE training for the upper/ lower extremities and trunk muscles provide the ability to work and reduce the kinesiophobia status of Sarcopenia patients. Combination of LAT or MAT exercises with PRE training provides both the effects of aerobic and resistance training, which can improve the overall quality of life.

The difference in clinical and psychological variables in low intensity and moderate intensity aerobic training in older adults is due to its variations in parameters such as frequency, intensity, time and mode 
of execution of exercises. Also, the muscle reaction to different exercise training protocols may be reduced in older adults when compared to younger people, which shows the physiological reserve in different stages of life. ${ }^{43}$ The combined aerobic and progressive resistance training program may help to overcome this problem in sarcopenia patients as agreed by Cruz Jentoff $A J$ et al and Deutz NE et al. ${ }^{44,45}$ Tieland et al ${ }^{46}$ noticed that combined exercise training with adequate protein intake improve muscle strength, physical performance and quality of life in frail older patients than exercise training alone.

Few limitations have been noticed during the execution of the whole trial. First, the authors felt the sample size of this trial was not sufficient for generalization of the reports, even though the sample size was calculated by previous pilot study. Second, all the participants were undergoing training at same time at same place; hence there is possibility of sharing of study information and masking of participants could be doubtful. Third, the study did not analyze the correlation between the clinical and psychological effects after low and moderate intensity aerobic training exercises. Lastly, there is absence of control group, which may show the real time effects of LAT and MAT exercise. Therefore, future studies should include a control group with more samples and should analyze the correlation between the clinical and psychological effects after low and moderate intensity aerobic exercises in COVID-19 older adults with Sarcopenia symptoms.

Combination of LAT or MAT exercises with PRT provides both the effects of aerobic and resistance training and can improve the clinical and psychological variables in community dwelling COVID-19 asymptomatic older adults with Sarcopenia symptoms. This study reports that low intensity aerobic training exercises improved the clinical (muscle strength and physical performance) and psychological (kinesiophobia and quality of life) aspects than moderate intensity aerobic training in COVID-19 asymptomatic older adults with Sarcopenia symptoms. At the same time, both types of aerobic training exercises have negligible or little role in increasing the muscle quantity - cross sectional area. The reports of the study would be helpful for the health professionals to prevent or postpone the negative consequences of Sarcopenia in older adults. High quality controlled clinical trials can be conducted at multicenter level with the involvement of multicomponent factors that can improve the health status of the COVID-19 infected older adults with Sarcopenia symptoms.

\section{Declarations}

Ethics approval and consent to participate: The study obtained the study ethical approval from Department Ethical Committee (DEC), Prince Sattam Bin Abdulaziz University, Al-Kharj, Saudi Arabia with the reference number of RHPT/020/044. Written consent was obtained from all the participants. The patients included in this study have not been reported in any other submission by me or anyone else.

Consent for publication: No individual data is contained in this publication.

Availability of data and materials: Data are not publically available, but can be obtained from corresponding author on request. 
Competing interest: None declared

\section{Funding: Self-funded study}

Author's contribution: Gopal Nambi (GN), Walid Kamal (WK), Anju Verma (AV), Arul Vellaiyan (AL)

Conceptualization: GN, WK, AV, AL. Data curation: GN, WK, AL. Formal analysis: GN, AV, AL. Methodology: GN, WK, AV, AL. Project administration: GN, WK. Supervision: GN, WK. Writing - original draft: GN, WK, AV, AL. Writing - review \& editing: GN, WK, AV, AL

Acknowledgement: This publication was supported by the Deanship of Scientific Research Prince Sattam bin Abdulaziz University, Al-Kharj, Saudi Arabia.

\section{References}

1. Morley JE, Vellas Editorial: COVID-19 and older adults. J Nutr Health Aging 2020;24:364-365.

2. Kai H, Kai M. Interactions of coronaviruses with ACE2, angiotensin II, and RAS inhibitors-lessons from available evidence and insights into COVID-19. Hypertens Res 2020, (Epub ahead of print).

3. Lin A, He ZB, Zhang S, Zhang JG, Zhang X, Yan WH. Early risk factors for the duration of SARS-CoV-2 viral positivity in COVID-19 Clin Infect Dis 2020; (Epub ahead of print).

4. Rosenberg IH. Sarcopenia: origins and clinical relevance. The Journal of nutrition 1997; 127(5 Suppl):990S-1S.

5. Vellas B, Fielding RA, Bens $C$ et al. Implications of ICD-10 for sarcopenia clinical practice and clinical trials: report by the International Conference on Frailty and Sarcopenia Research Task Force. J Frailty Aging 2018;7:2-9.

6. Lim WS, Liang CK, Assantachi P, Auyeng TW, Kang L, Lee WJ et al. COVID-19 and older people in Asia: Asian Working Group for Sarcopenia calls to action Geriatr Gerontol Int 2020;20:547-558.

7. Bauer J, Morley JE, Schols AMWJ, Ferrucci L, Cruz-Jentoft AJ, Dent E, et Sarcopenia: a time for action. An SCWD position paper. J Cachexia Sarcopenia Muscle 2019;10:956-961.

8. Dent E, Morley JE, Cruz-Jentoft AJ, Arai H, Krithevsky SB, Guralnik J, et al. International clinical practice guidelines for sarcopenia (ICFSR): screening, diagnosis and J Nutr Health Aging 2018;22:1148-1161.

9. Abate M, Di lorio A, Di Renzo D, Paganelli R, Saggini R, Abate Frailty in the elderly: the physical dimension. Europa medicophysica 2007;43(3):407-15.

10. Rolland Y, Czerwinski S, Van Kan GA et al. Sarcopenia: its assessment, etiology, pathogenesis, consequences and future Journal of Nutrition, Health and Aging 2008;12(7):433-450, 2008.

11. Carod-Artal FJ. Neurological complications of coronavirus and COVID-19. Rev Neurol 2020;70:311322.

12. Conti P, Ronconi G, Caraffa A, Gallenga CE, Ross R, Frydas I, et al. Induction of pro-inflammatory cytokines (IL-1 and IL-6) and lung inflammation by Coronavirus-19 (COVI-19 or SARS-CoV-2): anti- 
inflammatory strategies. J Biol Regul Homest Agents 2020;34.

13. McGonagle D, Sharif K, O'Regan A, Bridgewood The role of cytokines including interleukin- 6 in COVID-19 induced pneumonia and Macrophage activation syndrome-like disease. Autoimmun Rev 2020;19:102537.

14. Sheahan TP, Sims AC, Zhou S, Graham RL, Pruijssers AJ, Agostini ML, et An orally bioavailable broad-spectrum antiviral inhibits SARS-CoV-2 in human airway epithelial cell cultures and multiple coronaviruses in mice. Sci Transl Med 2020 (Epub ahead of print);12:eabb5883.

15. Wandrag L, Siervo M, Riley HL, Khosravi M, Fernandez BO, Leckstrom CA, et al. Dose hypoxia play a role in the development of sarcopenia in humans? Mechanistic in-sights from the Caudwell Xtreme Everest Redox Biol 2017;13:60-68.

16. Izquierdo M, Morley JE, Lucia A. Exercise in people over 85. BMJ 2020;368:m402.

17. Vellas B, Fielding RA, Bens $C$ et al. Implications of ICD-10 for sarcopenia clinical practice and clinical trials: report by the International Conference on Frailty and Sarcopenia Research Task Force. J Frailty Aging 2018;7:2-9.

18. Pasini E, Le Douairon Lahaye S, Flati V et Effects of treadmill exercise and training frequency on anabolic signaling pathways in the skeletal muscle of aged rats. Experimental Gerontology 2012;47(1):23-28.

19. Landi F, Marzetti E, Martone AM, Bernabei R, Onder G. Exercise as a remedy for Current Opinion in Clinical Nutrition and Metabolic Care 2014;17(1):25-31.

20. Liu CJ, Latham NK. Progressive resistance strength training for improving physical function in older adults. Cochrane Database Syst Rev 2009;2009(3):CD002759.

21. Sipers WM, Verdijk LB, Sipers SJ et al. The Martin vigori- meter represents a reliable and more practical tool than the Jamar dynamometer to assess handgrip strength in the geriat- ric patient. $J$ Am Med Dir Assoc 2016;17:466.e1-7.

22. Jones CJ, Rikli RE, Beam WC. A 30-s chair-stand test as a measure of lower body strength in community-residing older Res Q Exerc Sport 1999;70:113-9.

23. Beaudart C, McCloskey E, Bruyere $O$ et al. Sarcopenia in daily practice: assessment and management. BMC Geriatr 2016;16:170.

24. Rydwik E, Bergland A, Forsen $L$ et al. Investigation into the reliability and validity of the measurement of elderly people's clinical walking speed: a systematic review. Physiother Theory Pract 2012;28:23856.

25. Tkachuk G A, Harris C A. Psychometric properties of the tampa scale for kinesiophobia-11 (TSK11) Journal of Pain2012;13(10):970-977.

26. Beaudart C, Biver E, Reginster JY et al. Validation of the SarQoL(R), a specific health-related quality of life questionnaire for Sarcopenia. J Cachexia Sarcopenia Muscle 2017; 8: 238-44.

27. Yoo J, Choi H, YC. Mean Hand Grip Strength and Cut-off Value for Sarcopenia in Korean Adults Using KNHANES VI. J Korean Med Sci 2017;32(5): 868-872. 
28. Marzetti E, Calvani R, Landi F et Innovative medicines initiative: the SPRINTT project. The Journal of Frailty \& Aging 2015;4(4):207-208.

29. Izquierdo M, Morley JE, Lucia A. Exercise in people over 85. BMJ 2020;368:m402.

30. Caspersen CJ, Powell KE, Christenson G. Physical activity, exercise and physical fitness: definitions and distinc- tions for health-related Public Health Reports 1985;100(2):126-131.

31. Cartee GD, Hepple RT, Bamman MM, Zierath JR. Exercise promotes healthy aging of skeletal Cell Metabolism 2016;23(6);1034-1047.

32. Marzetti E, Calvani R, Cesari M et Mitochondrial dysfunction and sarcopenia of aging: from signaling pathways to clinical trials. International Journal of Biochemistry and Cell Biology 2013;45(10):22882301.

33. Rejeski WJ, Marsh AP, Chmelo E, et al. The lifestyle interventions and independence for elders pilot (life-p): 2-year follow-up. J Gerontol A Biol Sci Med Sci 2009;64:462-467.

34. Pasini E, Le Douairon Lahaye S, Flati V et Effects of treadmill exercise and training frequency on anabolic signaling pathways in the skeletal muscle of aged rats. Experimental Gerontology $2012 ; 47(1): 23-28$.

35. Roth SM, Ivey FM, Martel GF, et al. Muscle size responses to strength training in young and older men and women. J Am Geriata Soc 2001;49:1428-1433.

36. Goto K, Ishii N, Sugihara S, Yoshioka T, Takamatsu K. Effects of resistance exercise on lipolysis during subsequent submaximal exercise. Med Sci Sports Exerc 2007;39:308-315.

37. Calvani R, Joseph AM, Adhihetty PJ et Mitochondrial pathways in sarcopenia of aging and disuse muscle atrophy. Biological Chemistry 2013;394(3):393-414.

38. Bowen TS, Schuler G, Adams V. Skeletal muscle wasting in cachexia and sarcopenia: molecular pathophysiology and impact of exercise Journal of Cachexia, Sarcopenia and Muscle 2015;6(3):197-207.

39. Rejeski WJ, Marsh AP, Chmelo E, et al. The lifestyle interventions and independence for elders pilot (life-p): 2-year follow-up. J Gerontol A Biol Sci Med Sci 2009;64:462-467.

40. Binder EF, Brown M, Sinacore DR, Steger-May K, Yarasheski KE, Schechtman KB. Effects of extended outpatient rehabilitation after hip fracture: a randomized controlled trial. JAMA 2004;292:837-846.

41. Holviala J, Ha“kkinen A, Karavirta L, et Effects of combined strength and endurance training on treadmill load carrying walking performance in aging men. J Strength Cond Res 2010;24:1584-1595.

42. Granacher U, Gollhofer A, Hortobagyi T, Kressig RW, Muehlbauer T. The importance of trunk muscle strength for balance, functional performance, and fall prevention in seniors: a systematic review. Sports Med 2013;43:627-641.

43. Cartee GD, Hepple RT, Bamman MM, Zierath JR. Exercise promotes healthy aging of skeletal Cell Metabolism 2016;23(6):1034-1047.

44. Cruz-Jentoft AJ, Landi F, Schneider SM et Prevalence of and interventions for sarcopenia in ageing adults: a systematic review. Report of the International Sarcopenia Initiative (EWG- SOP and IWGS). 
Age and Ageing 2014;43(6):48-759.

45. Deutz NEP, Bauer JM, Barazzoni R et al. Protein intake and exercise for optimal muscle function with aging: recommendations from the ESPEN Expert Clinical Nutrition 2014;33(6):929-936.

46. Tieland $\mathrm{M}$, Dirks ML, van der Zwaluw $\mathrm{N}$ et Protein supplementation increases muscle mass gain during prolonged resistance-type exercise training in frail elderly people: a ran- domized, double-blind, placebo-controlled trial. Journal of the American Medical Directors Association 2012;13(8):713719.

Figures

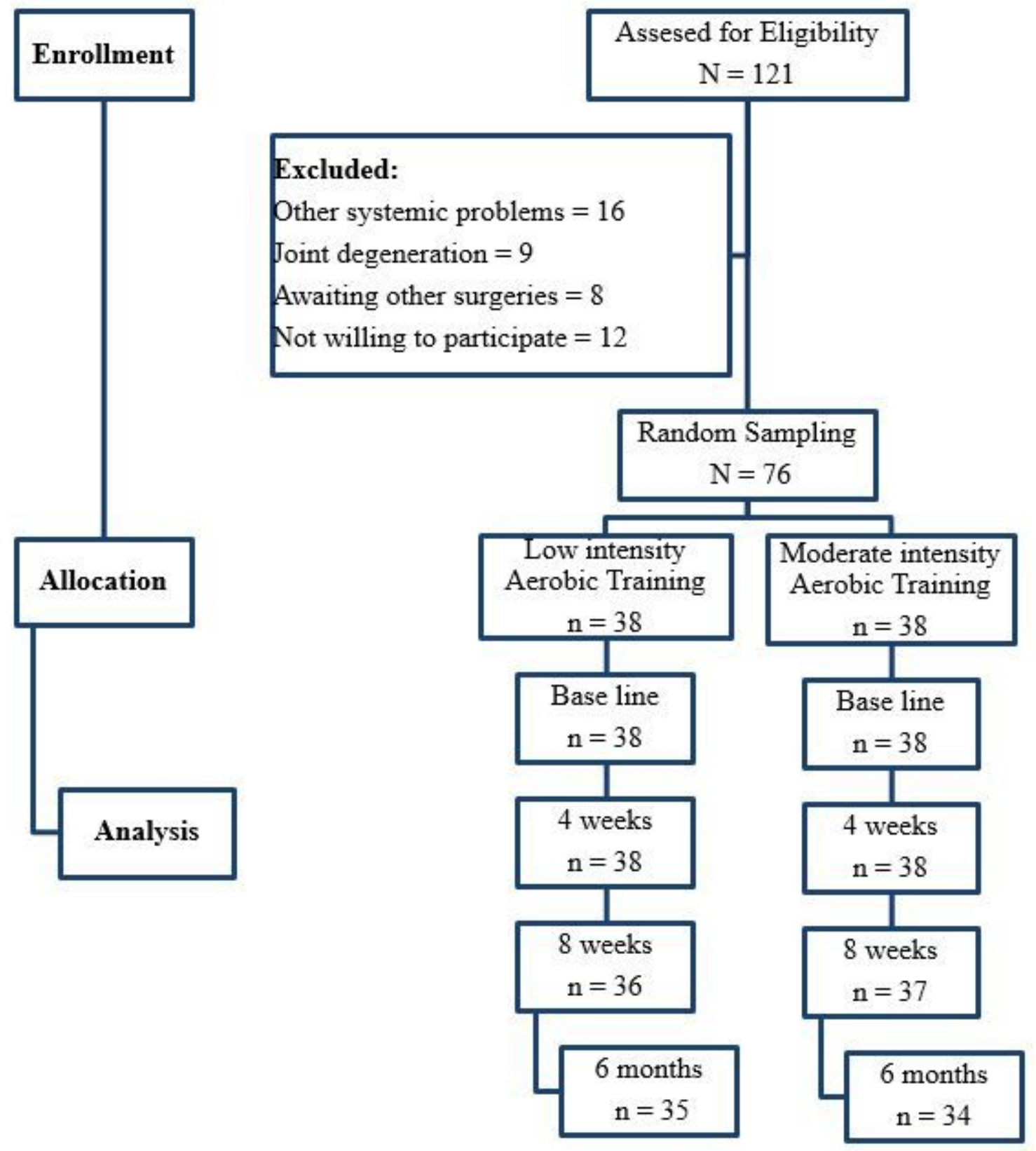

Figure 1 
Flow chart showing the study details
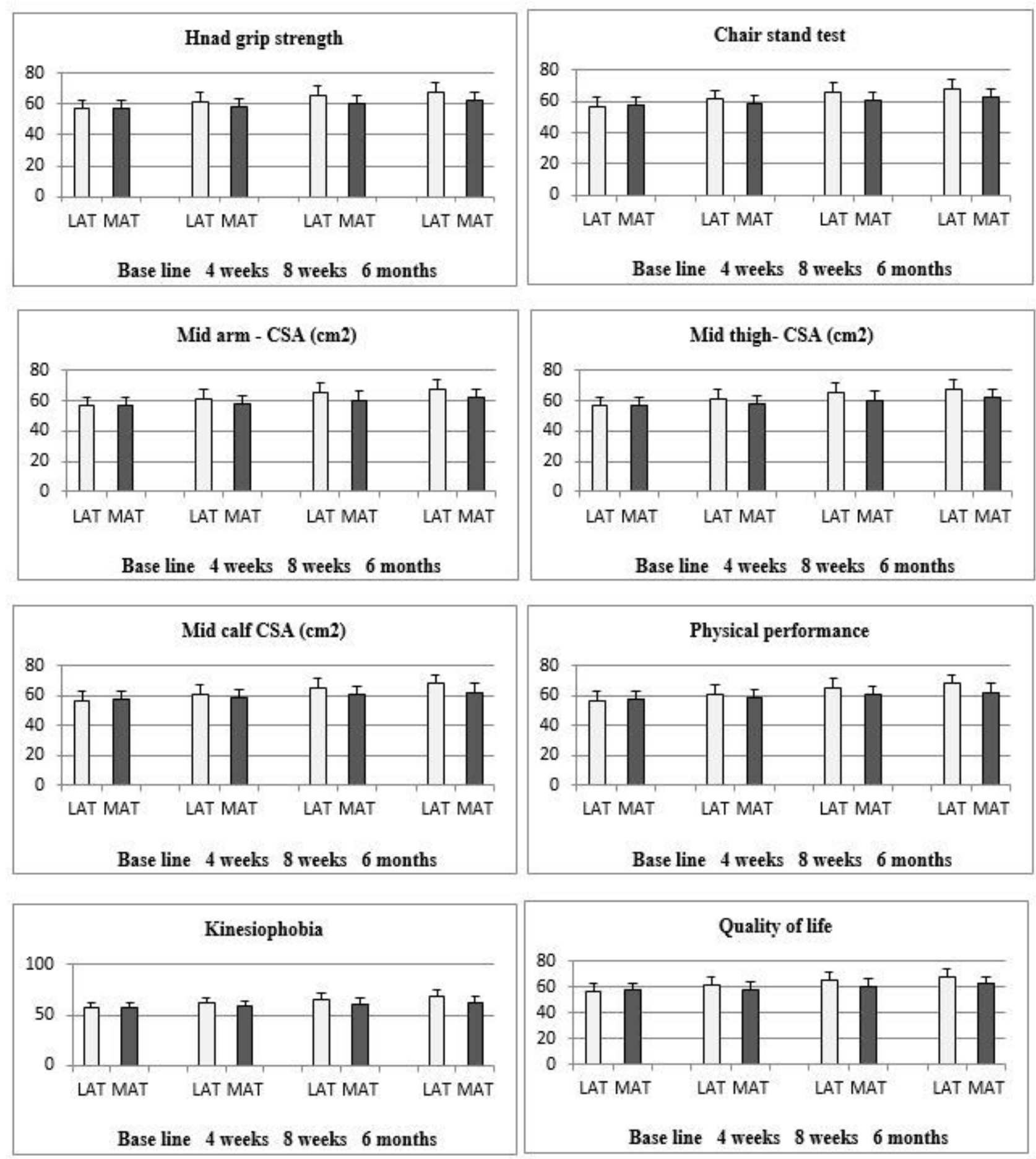

LAT - Low intensity aerobic training, MAT - Moderate intensity aerobic training

Figure 2

Mean values of primary and secondary outcome variables scores of LAT and MAT groups 